University of Vermont

UVM ScholarWorks

8-1-2011

\title{
The effects of climate change on density-dependent population dynamics of aquatic invertebrates
}

\author{
Edmund M. Hart \\ University of Vermont \\ Nicholas J. Gotelli \\ University of Vermont
}

Follow this and additional works at: https://scholarworks.uvm.edu/casfac

Part of the Climate Commons

\section{Recommended Citation}

Hart EM, Gotelli NJ. The effects of climate change on density-dependent population dynamics of aquatic invertebrates. Oikos. 2011 Aug;120(8):1227-34.

This Article is brought to you for free and open access by the College of Arts and Sciences at UVM ScholarWorks. It has been accepted for inclusion in College of Arts and Sciences Faculty Publications by an authorized administrator of UVM ScholarWorks. For more information, please contact scholarworks@uvm.edu. 
Oikos 120: 1227-1234, 2011

doi: $10.1111 /$ j.1600-0706.2011.18707.x

(C) 2011 The Authors. Oikos (C) 2011 Nordic Society Oikos

Subject Editor: Matthijs Vos. Accepted 11 January 2011

\title{
The effects of climate change on density-dependent population dynamics of aquatic invertebrates
}

\author{
Edmund M. Hart and Nicholas J. Gotelli \\ E. M. Hart (ehart1@uvm.edu) and N. J. Gotelli, Dept of Biology, Univ. of Vermont, Burlington, VT 05404, USA.
}

\begin{abstract}
Global climate change has the potential to alter aquatic communities through changes in evapotranspiration and increased variability in precipitation. We used aquatic mesocosms to test the impacts of variable precipitation on population dynamics of common mosquito (Culicidae) and midge (Chironomidae) larvae that inhabit vernal pools. In a mixed deciduous forest in northern Vermont, USA, we orthogonally crossed seven levels of mean water level (increased rainfall) with seven levels of water level coefficient of variation (more variable rainfall) to simulate a broad array of climate change scenarios in 49 experimental mesocosms.

The average abundance of Culicidae was highest at low water levels, whereas the average abundance of Chironomidae was highest at higher water levels and low variability in water level. Treatments and environmental and spatial covariates collectively explained $49 \%$ of the variance in mean abundance. For both taxa, we fit hierarchical Bayesian models to each 16-week time series to estimate the parameters in a Gompertz logistic equation of population growth with density dependence. We found that Culicidae population growth rate increased with decreasing water levels and that $87 \%$ of the variance in Chironomidae density dependence could be explained by treatment. Collectively, these results suggest that climate change can alter abundances aquatic invertebrate taxa but not necessarily through the same mechanism on all populations. In the case of Culicidae the abundance is affected by changes in growth rate, and in Chironomidae by changes in the strength of density dependence.
\end{abstract}

Over the past decade, ecologists have used field and laboratory experiments to document population and community responses to global climate change, including responses to elevated $\mathrm{CO}_{2}$ (Ainsworth and Long 2005), increased temperature (Visser and Holleman 2001), and increased variability in precipitation (Suttle et al. 2007). Some correlative studies have also examined the relationship between climate and population dynamics (Mysterud et al. 2001, Halkka et al. 2006, Turner et al. 2006, Tavecchia et al. 2007, Lima et al. 2008, Ogutu et al. 2008) by testing for relationships between time series of abundance and environmental covariates (Ives 1995, Ådahl et al. 2006). Experimental studies of the effects of climate change may provide stronger evidence and more powerful results for forecasting (Krebs and Berteaux 2006), but they are still uncommon (Richmond et al. 2007). Using a manipulative field experiment, we asked how climate change impactson the mean and variance of water level affect the population dynamics of aquatic invertebrates in aquatic mesocosms.

Studies on population dynamics and climate change usually rely on either long data sets that span contemporary climate change (Adler and HilleRisLambers 2008, van de Pol et al 2010) or time series data that span natural climatic fluctuation such as the North Atlantic Oscillation (NAO) (Sæther et al 2000, Coulson et al 2001). These studies construct models that examine how population size and density dependence track changes in the mean value of a variable such as NAO index (Sæther et al 2000), temperature or precipitation (Adler and HilleRisLambers 2008). While the mean values of precipitation and temperatures are increasing due to climate change, the variance around those means is also expected to increase (Hayhoe et al 2008). It is equally important therefore that we understand how both the mean and variance of a variable affect population dynamics (Benedetti-Cecchi 2003). To that end van de Pol et al (2010) used a long term data set for oyster catchers to construct demographic that included both mean temperature and temperature variability. They found that temperature mean was more important than variability for population persistence, but variability in temperature was important for juvenile survivorship. The results we present here complement work such as this by testing the importance the mean and variance in climate variables with a manipulative field experiment. We created forty-nine artificial vernal pond mesocosms in northern Vermont, and fully crossed seven levels of mean water level with seven levels of the coefficient of variation $(\mathrm{CV})$ in water depth to mimic climate change scenarios in vernal ponds due to altered precipitation. Then using non-destructive in-situ sampling and we monitored populations of larval Culicidae 
and Chironomidae over the course of a single field season. With this data we constructed population dynamic models for each taxa and examined how model parameters varied with changes the mean and variance of water level..

We predicted that both taxa would have increased population size and decreased density dependence in deeper and less variable mesocosms. Deeper water levels should increase resources, habitat volume and thereby reducing density dependent mortality, whereas a higher CV generates more variable environments which tends to increase extinction rates and population variability (Boyce et al 2006, van de Pol et al 2010), especially in response to changes in rainfall (Drake 2005).

\section{Methods}

\section{Study system}

Regional climate change models predict a warming of $2^{\circ}$ to $3.5^{\circ} \mathrm{C}$ by 2100 under low emissions scenarios, and an even larger increase under high emission scenarios (Frumhoff et al. 2006). Climate change scenarios for the northeast USA also predict an increased water budget in the winter/spring and increased deficit in the summer/fall (Moore et al. 1997). Precipitation events are likely to become more variable, with longer periods of drought followed by more intense deluges (Sun et al. 2007, Kendon et al. 2008). Vernal ponds are fishless habitats that fill in the spring (vernal) or fall (autumnal) and hold water for at least four months (Zedler 2003) and represent ideal systems to study the effects of climate change. Climate change will alter these systems through increased evapotranspiration and more variable precipitation. Increased winter precipitation will increase initial pond volume, and more variable spring summer rainfall combined with greater evapotranspiration will increase the variability through the season of pond water level.

Our mesocosms supported a variety of invertebrate taxa that are found in natural vernal pools. Non-destructive insitu field sampling of tubs did not allow us to consistently distinguish individuals to genus and species, so we restricted our analyses to the family level. The insect families Culicidae (mosquitoes) and Chironomidae (non-biting midges) were common enough in all 49 replicates (at least $80 \%$ of the observations were $>0$ in all 49 treatments) tojustify time series analysis. Collectively, these families constitute the majority of invertebrate biomass in vernal pools (Colburn 2004), and account for $90 \%$ of the total abundance of invertebratessampled from our mesocosms. In vernal pools and many other aquatic habitats, these taxa play major ecological roles as omnivorous filter feeders (Culicidae) and detritivores (Chironomidae).

Forty-five species of Culicidae have been recorded in Vermont, 10 of which have container-dwelling larva (Graham 2008). We identified voucher samples to species and found five species present: Anopheles punctipennis, Culex restuans, C. pipiens, Ochlerotatus japonicus and O. triseriatus. In our samples, Culex spp. were most common, and Anopheles was most rare. Culex restuans tends to be most abundant in Vermont from June to August, and C. pipiens is most abundant from July to September (A. Graham pers. comm.). Chironomidae voucher samples were identified only tofamily because of the difficulty and time needed to identify material to the genus or species level. A 2003 survey of vernal ponds found that five most common genera of Chironomidae were Chironomus, Polypedilium, Limnophyes, Larsia and Phaenopsectra (Burnham and Sorensen 2003). Most of the species in our mesocosms were case-building Chironomids (Hartunpubl.), that rarely leave their tubes and feed only on material that they filter or gather from around their tubes (Armitage et al. 1994).

\section{Experimental design}

The experiment was established in a $25 \times 25 \mathrm{~m}$ plot in a second-growth deciduous forest at the Univ. of Vermont

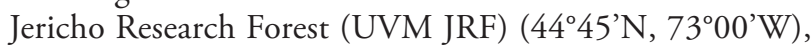
which has naturally occurring vernal ponds within the forest. Our experiment consisted of seven levels each of two treatments (mean water level and coefficient of variation in water level; Benedetti-Cecchi 2003) applied to 49 artificial mesocosms in a fully-crossed response surface design. Although this design sacrifices replication, it allows a large parameter space to be efficiently explored with many levels of each factor (Inouye 2001, McCoy and Bolker 2008). Mean water levels were expressed as a percentage of maximum container volume $(20 \%, 30 \%, 40 \%, 50 \%, 60 \%$, $70 \%, 80 \%$ treatments). Coefficient of variation (CV) levels ranged from 0 to $60 \%$. We parameterized a unique gamma distribution for each tub by first calculating the standard deviation as $\sigma=\mu \times C V$ where $\mu$ is the mean water level and CV is the coefficient of variation in water level. Each mean and standard deviation was then used to find the shape and rate parameters of a gamma distribution using the 'optim' function in R 2.10 (R Development Core Team 2010). We then simulated weekly water levels for each mesocosm by taking 16 random draws from each unique gamma distribution, having bounds between 0 and $\infty$, because it is the parametric distribution most often used to model rainfall (Husak et al. 2007).

This design encompasses a broad parameter space of future intraseasonal hydrological impacts on vernal pools. The climate change predictions of more rainfall in the winter and more variable rainfall in the spring and summer will have a variety of interannual effects beyond the scope of this study (e.g. changes in phenology), but this experiment addresses the impact of within-year variability. Differing mean water levels represent different amounts of winter precipitation melt. Climate change models forecast more winter snowfall in the northeastern USA (Kendon et al. 2008). At the same time, summer precipitation is expected to become more variable, with more days of intense storms (Sun et al. 2007). We simulated this increased variability by altering the coefficient of variation in water level.

\section{Establishment of treatments}

Each experimental unit was a 205-l high-density polyethylene plastic tub $(100 \times 50 \times 33 \mathrm{~cm})$. Natural vernal pools in Vermont have an average surface area of $86 \mathrm{~m}^{2}$ (range 20-967 $\mathrm{m}^{2}$ ) and an average depth of $0.4 \mathrm{~m}$ (range 0.07-0.93 m; Burnham and Sorensen 2003). Our 
mesocosms had a relatively small area, but did have realistic depth ranges. Mesocosms were laid out in April 2007 in an octagonal array, with each tub approximately $1.5 \mathrm{~m}$ from its nearest neighbor. Plastic fencing was installed around the entire array to prevent dogs and other large vertebrates from disturbing the mesocosms. In contrast to many classic cattle-tank experiments (Wilbur 1987), our mesocosms were left open for the duration of the experiment to allow for external colonization. Each of the 49 unique treatments was assigned randomly to one of the replicates. We seeded each mesocosm with approximately $300 \mathrm{ml}$ of water from a well-mixed plankton tow and $4 \mathrm{l}$ of an innoculum of detritus and insects from a nearby vernal pond. We filled each mesocosm with leaf litter from the surrounding forest to achieve a detrital depth of 1-2 cm. All mesocosms were then filled to their initial depth with filtered water from a nearby spring-fed well. We measured water levels weekly, and adjusted them according to their prescribed treatment by either adding well water, or drawing water levels down with a 1136 lph battery-powered pump. The pump hose was covered by two layers of $1 \mathrm{~mm}$ mesh to prevent macroinvertebrate capture. At each census, we also measured $\mathrm{pH}$, dissolved oxygen (DO), water temperature, air temperature and turbidity. We sampled each mesocosm by sweeping a $7.6 \times 10 \mathrm{~cm}$ net $(3 \mathrm{~mm}$ mesh) once through the water column, and once through the benthic material. To avoid destructive sampling, all animals were transferred to a sorting tray in the field, counted, identified to the family level, and immediately returned to their mesocosm. We sampled invertebrates, measured abiotic variables, and then adjusted water levels weekly from 5 April - 28 August 2007, yielding 16 consecutive observations for each container.

\section{Statistical analysis}

We encountered some zeroes in our weekly counts so we first added 1 to every number and then log transformed them to normalize our data (McArdle et al. 1990) in all our analyses. Average abundances were calculated by taking the mean of transformed abundances, effectively the geometric mean.

\section{Average population size}

With each mesocosm representing a single observation $(\mathrm{n}=49)$, we next fit a multiple regression model with main effects for mean water level (MWL) and CV (WLCV) and their interaction:

$$
\begin{aligned}
\mathrm{y}_{\mathrm{i}}= & \beta_{0}+\beta_{1} \times \mathrm{MWL}+\beta_{2} \times \mathrm{WLCV}+\beta_{3} \times \mathrm{MWL} \\
& \times \mathrm{WLCV}+\varepsilon_{\mathrm{i}}
\end{aligned}
$$

For each taxon, we calculated the $\mathrm{R}^{2}$ of the fitted model and the statistical significance of the regression coefficients.

\section{Effects of environmental covariates on average abundance} In order to take both unknown spatial effects and environmental covariates into account, we used backwards stepwise regression to select the best model out of all our measured covariates. The values for covariates represent the average of sixteen measurements taken from each tub at the time we sampled invertebrates. The full general model was:

$$
\begin{aligned}
\mathrm{y}_{\mathrm{i}}= & \beta_{0}+\beta_{1} \times \mathrm{MWL}+\beta_{2} \times \mathrm{WLCV}+\beta_{3} \times \mathrm{MWL} \\
& \times \mathrm{WLCV}+\beta_{4} \times \text { D.O. }+\beta_{5} \times \mathrm{pH}+\beta_{6} \\
& \times \text { Air temp }+\beta_{7} \times \text { Water temp }
\end{aligned}
$$

where MWL is mean water level, WLCV is water level CV, $y_{i}$ is the mean of $\log (x+1)$ abundances of either Culicidae or Chironomidae in tub i, Air temp is measured air temperature, $\mathrm{pH}$ is $\mathrm{pH}, \mathrm{DO}$ is dissolved oxygen, Water temp is measured water temperature, Xcor and Ycor are the spatial coordinates of the replicate, $\beta_{0}$ to $\beta_{10}$ are fitted regression coefficients, and $\varepsilon_{\mathrm{i}}$ is the residual error. Model selection was conducted in R 2.10 (R Core Development Team 2010) with the $\operatorname{step}()$ function in the stats package.

\section{Population dynamics and density dependence}

To analyze the population dynamics of each time series, we used a hierarchical normal Bayesian model with a structure based on the population dynamic framework of Royama (1992) and Berryman (1999). We began with a discrete time Ricker equation (Royama 1992)

$\mathrm{N}_{\mathrm{t}}=\mathrm{N}_{\mathrm{t}-1} \exp \left[\mathrm{r}_{0}\left(1-\frac{\mathrm{N}_{\mathrm{t}-1}}{\mathrm{~K}}\right)\right]$

and removed the exponent by dividing both sides by $\mathrm{N}_{\mathrm{t}-1}$ and taking the log of both sides.

$\ln \left(\frac{\mathrm{N}_{\mathrm{t}}}{\mathrm{N}_{\mathrm{t}-1}}\right)=\mathrm{r}_{0}\left(1-\frac{\mathrm{N}_{\mathrm{t}-1}}{\mathrm{~K}}\right)$

The quantity $\ln \left(\frac{\mathrm{N}_{\mathrm{t}}}{\mathrm{N}_{\mathrm{t}-1}}\right)$ in Eq. 2 is the population growth rate at time $t$ or $r_{t}$. We handled zero values by first transforming all values of $\mathrm{N}_{\mathrm{t}}$ to $\mathrm{N}_{\mathrm{t}}+1$, making Eq. $2 \ln \left(\frac{\mathrm{N}_{\mathrm{t}}+1}{\mathrm{~N}_{\mathrm{t}-1}+1}\right)$. This formulation yields a discrete-time linear equation of density dependence (Dennis and Taper 1994).

$r_{t}=\alpha+\beta N_{t-1}$

The parameters in Eq. 3 have a simple ecological interpretation: $\alpha$ is the population growth rate and $\beta$ is the strength of density-dependence. With 49 unique time-series we used a hierarchical framework to construct full model for all series in which the growth rate at time $t$ is a function of water level $\mathrm{j}$ and $\mathrm{CV} \mathrm{k}$. An alternative form of this basic equation is the Gompertz logistic (GL) growth equation, which is the same as Eq.3, but uses the natural $\log$ of $\mathrm{N}_{\mathrm{t}}+1$ (Ives et al. 2003). We used a GL model because our data showed an exponential decay of $\mathrm{r}$ with population size, which is linear in the GL model (Yang et al. 2008):

$\mathrm{r}_{\mathrm{t} \mathrm{k} \mathrm{k}} \sim \mathrm{N}\left(\alpha_{\mathrm{jk}}+\beta_{\mathrm{jk}} X_{[\mathrm{t}-1] \mathrm{jk}}, \sigma_{\mathrm{r}}^{2}\right)$

We are modeling the growth rate $\mathrm{r}$ at time $\mathrm{t}$ at water level $j$ and $\mathrm{CV} \mathrm{k}$ as an effect of a unique growth rate $\alpha_{\mathrm{jk}}$ and 
$\alpha$ density dependent term $\beta_{\mathrm{jk}}$ on the log of the population size plus one at the previous time step $\mathrm{X}_{[\mathrm{t}-1] \mathrm{k} \mathrm{k}}$ is the logarithm of population size. We modeled the parameters $\alpha$ and $\beta$ as multivariate normal variables. We modeled the effects of water level and $\mathrm{CV}$ as rescaled normal variables with a mean of 0 .

$\left(\begin{array}{c}\alpha_{\mathrm{jk}} \\ \beta_{\mathrm{jk}}\end{array}\right)=\left(\begin{array}{l}\mu_{\alpha} \\ \mu_{\beta}\end{array}\right)+\left(\begin{array}{l}\phi_{\alpha} \\ \phi_{\beta}\end{array}\right)+\left(\begin{array}{l}\gamma_{\alpha} \\ \gamma_{\beta}\end{array}\right)+\left(\begin{array}{c}\phi_{\alpha} \times \gamma_{\alpha} \\ \phi_{\beta} \times \gamma_{\beta}\end{array}\right)$

Each term in Eq. 5 except for $\mu$ was modeled as:

$\mathrm{B}_{\mathrm{j}} \sim \operatorname{MVN}\left(\mathrm{U}, \Sigma_{\mathrm{B}}\right)$

where $U=(0,0)$, and $\Sigma_{\mathrm{B}}$ is the variance-covariance matrix for the different effect sizes. This formulation allowed us to measure the covariance between slopes and intercepts in the GL model.

We fit the models using Markov-chain Monte Carlo algorithms written in R 2.10 (R Core Development Team 2010) using Gibbs samplers. We ran three chains with random starting points and 10000 iterations each with noninformative priors. Convergence was assessed by plotting MCMC output and checking for autcorrelation and poor sample mixing, as well as using Gelman and Rubin's convergence statistic (Gelman and Rubin 1992) in the R package coda (Plummer et al. 2006). Individual estimates of slope and intercept parameters were then tested against treatment in a two-factor response surface multiple regression.

\section{Results}

\section{Average abundance}

Abundance of each taxon, averaged across the entire timeseries, was significantly affected by water-level treatments. For Culicidae, average abundance decreased with increasing water level $\left(\beta_{1}=-0.04, p=0.008\right)$ but was not significantly affected by water level $\mathrm{CV}\left(\beta_{2}=-1.02, \mathrm{p}=0.21\right.$; Fig. 1). The model explained $27 \%$ of the total variation in average Culicidae abundance. For Chironomidae, average abundance was not affected by mean water level $\left(\beta_{1}=\right.$ $0.006, p=0.58$ ) but was affected by the $\mathrm{CV}$ of water level $\left(\beta_{2}=-2.26, p=0.0005\right)$. However, the interaction between mean water level and CV was significant $\left(\beta_{3}=\right.$ $0.097, p=0.006$ ) and abundance was unusually low when both mean water level and CV were low (Fig. 1). The model explained $49 \%$ of the total variance in average Chironomidae abundance.

\section{Effects of environmental covariates on average abundance}

There was a moderate degree of intercorrelation between abundances and measured environmental covariates (Table 1). The model selection procedure identified the best model for Culicidae as:

$$
\begin{aligned}
\text { Culicidae }_{\mathrm{i}}= & 10.2-0.02 \times \mathrm{MWL}-0.45 \times \mathrm{WLCV}-0.32 \\
& \times \text { D.O. }-0.42 \times \text { Air temp }-0.06 \\
& \times \text { Xcor }-0.1 \times \text { Ycor }+\varepsilon_{\mathrm{i}}
\end{aligned}
$$

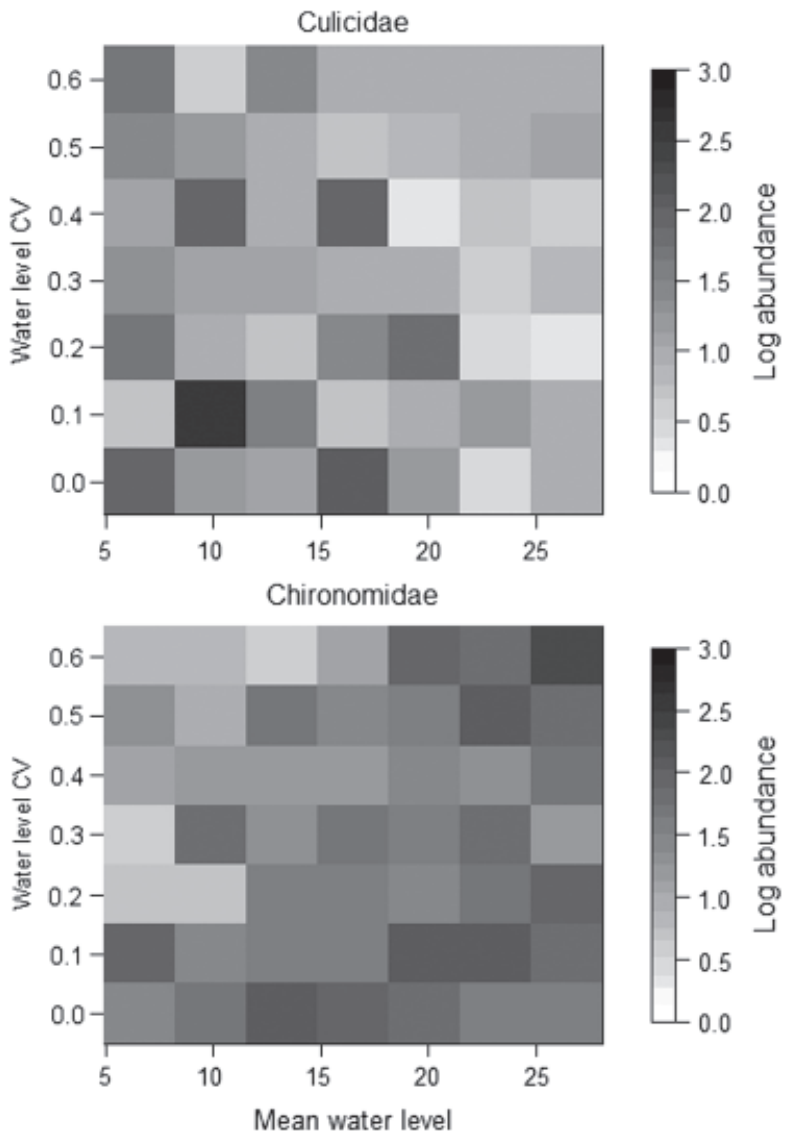

Figure 1. Mean log abundance for Culicidae (top panel), Chironomidae (bottom panel). Each square represents a single mesocosm with mean water level on the $\mathrm{x}$-axis and coefficient of water level variation on the $y$-axis. Lighter areas represent a small population size, and darker represent a large population size. Culicidae showed a negative response to both mean water level and water level CV. Chironomidae showed a positive relationship with mean water level, but a negative one with water level CV.

with an $\mathrm{R}^{2}$ of 0.49 . For Chironomidae the model selected was:

$\begin{aligned} \text { Chironomidae }_{\mathrm{i}}= & 1.57+0.007 \times \mathrm{MWL}-0.26 \times \mathrm{WLCV} \\ & +0.1 \times \mathrm{MWL} \times \mathrm{WLCV}\end{aligned}$

alsowith an $\mathrm{R}^{2}$ of 0.49 .Although each model was different, the two experimental treatment effects were always present in the final model. Culicidae responded to both treatments and a suite of environmental covariates as well as spatial location. Chironomidae, on the other hand, responded only to the treatments but not to any of the covariates.

\section{Population dynamics and density dependence}

Culicidae population growth rate $\alpha$ varied negatively with mean water level $(\mathrm{p}=0.0004)$ with an $\mathrm{R}^{2}$ of 0.43 , and the density dependent term $\beta$ varied negatively with both mean water level $(\mathrm{p}=0.006)$ and CV $(\mathrm{p}=0.04)$ with an $\mathrm{R}^{2}$ of 0.18 (Fig. 2). Population growth rate $\alpha$ for Chironomidae did not vary consistently with treatment $(\mathrm{p}=0.07$ for mean water level and $\mathrm{p}=0.02$ for $\mathrm{CV}, \mathrm{R}^{2}=0.13$ ) (Fig. 2). However, 
Table 1. Pearson correlation coeffecients between Culicidae and Chrionomidae abundance and environmental covariates and spatial coordinates of each mesocosm. Population averages represent the mean log abundance of all 16 time points for each mesocosm. Averages for other physical variables represent the mean over all sampling dates. Spatial coordinates represent the tubs position in a simple Cartesian grid-space. Significant Pearson product moment correlations $(\mathrm{p}<0.05)$ are bold and italicized.

\begin{tabular}{|c|c|c|c|c|c|c|c|}
\hline & Culicidae & Chironomidae & $\mathrm{pH}$ & Air temp & Water temp & $\mathrm{DO}$ & x-coord \\
\hline Culicidae & - & - & - & - & - & - & - \\
\hline Chironomidae & -0.21 & - & - & - & - & - & - \\
\hline $\mathrm{pH}$ & -0.24 & 0.05 & - & - & - & - & - \\
\hline Air temp & -0.06 & -0.18 & 0.32 & - & - & - & - \\
\hline Watertemp & 0.01 & -0.25 & 0.24 & 0.79 & - & - & - \\
\hline DO & -0.37 & 0.39 & -0.10 & -0.43 & -0.43 & - & - \\
\hline $\mathrm{x}$-coord & -0.32 & 0.32 & 0.03 & -0.27 & -0.15 & 0.32 & - \\
\hline$y$-coord & -0.03 & 0.14 & -0.44 & -0.86 & -0.73 & 0.46 & 0.09 \\
\hline
\end{tabular}

the density dependent term $\beta$ for Chironomideae responded strongly to treatment $\left(\mathrm{R}^{2}=0.87\right)$. Density dependence was strongest at low water levels and high CV $(\mathrm{p}=0.00001$ for mean water level and $\mathrm{p}=0.00001$ for CV) (Fig. 2).

\section{Discussion}

Both mean abundance (Fig. 1) and population model parameters (Fig. 2) in Culicidae and Chironomidae had different responses to the same treatment combinations. Culicidae had high abundance at low mean water levels (Fig. 1), whereas Chironomidae supported our initial hypothesis and had high abundance at high water levels with low CV (Fig. 1).
Time-series trajectories of population change in individual treatments provide insight into how population growth affects abundance (Fig. 3).Culicidae populations in different treatments showed similar population trajectories but with different growth rates $(\alpha)$, which resulted in high abundance in low mean water level tubs (Fig. 3). In contrast, Chironomidae abundance changed because of changes in the strength of density dependence $(\beta)$, with almost very weak density dependence in high mean water level and low CV treatments (dashed line Fig. 3).

These changes in population dynamic parameters that differ by taxa most likely reflect their different life histories. We believe that the higher growth rate at lower water levels in Culicidae is caused by female oviposition choice
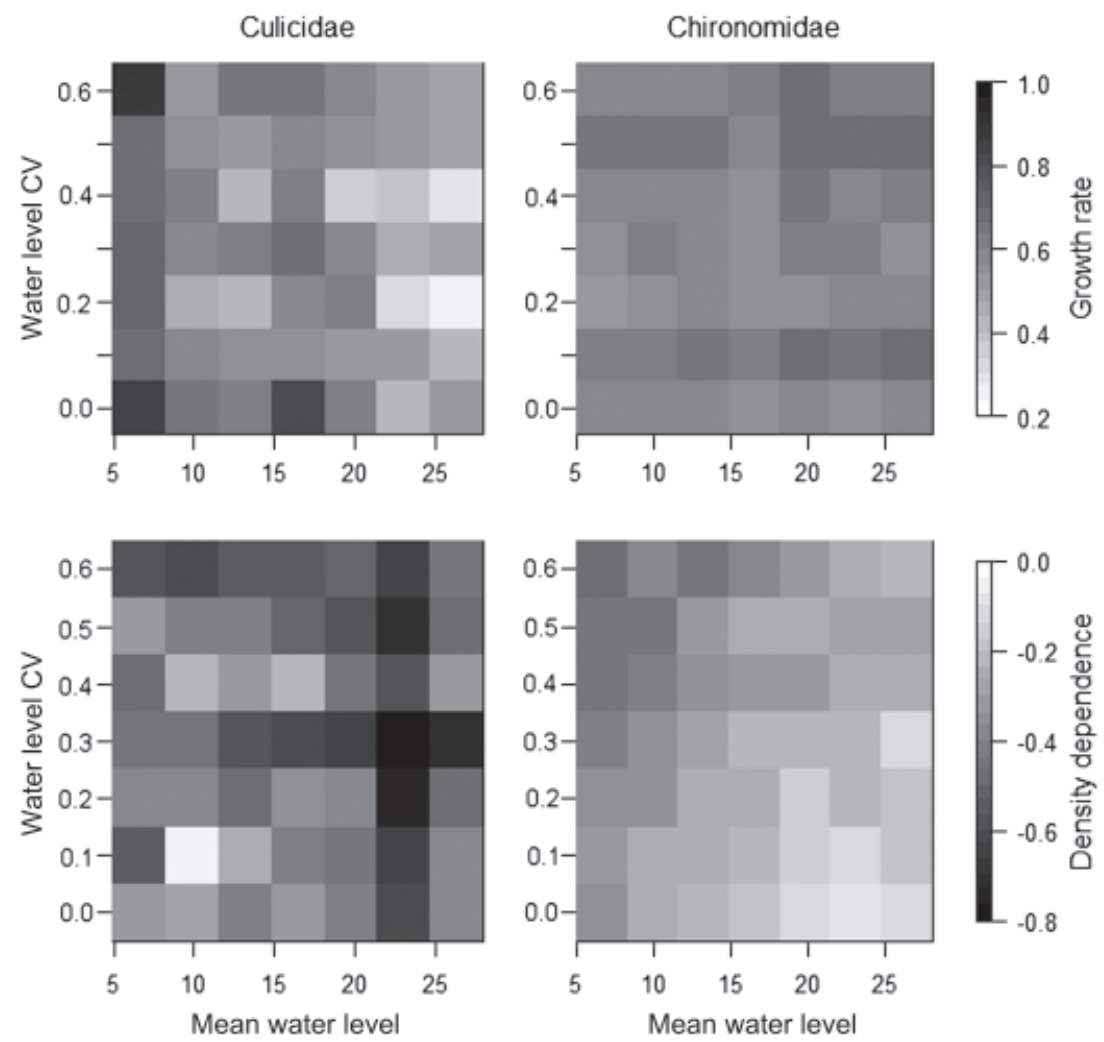

Figure 2. Estimates of the Gompertz logistic (GL) parameters for each treatment combination. Culicidae is in the left column with growth rate in the upper panel and density dependence in the lower panel, and Chironomidae is in the right column with growth rate in the upper panel and density dependence is the lower panel. Darker squares indicate either higher population growth rate or stronger density dependence. Treatments explained $43 \%$ of the variance in Culicidae growth rates, and $87 \%$ of the variance in Chironomidae density dependence, with low $\mathrm{R}^{2}$ values for the other parameters. 

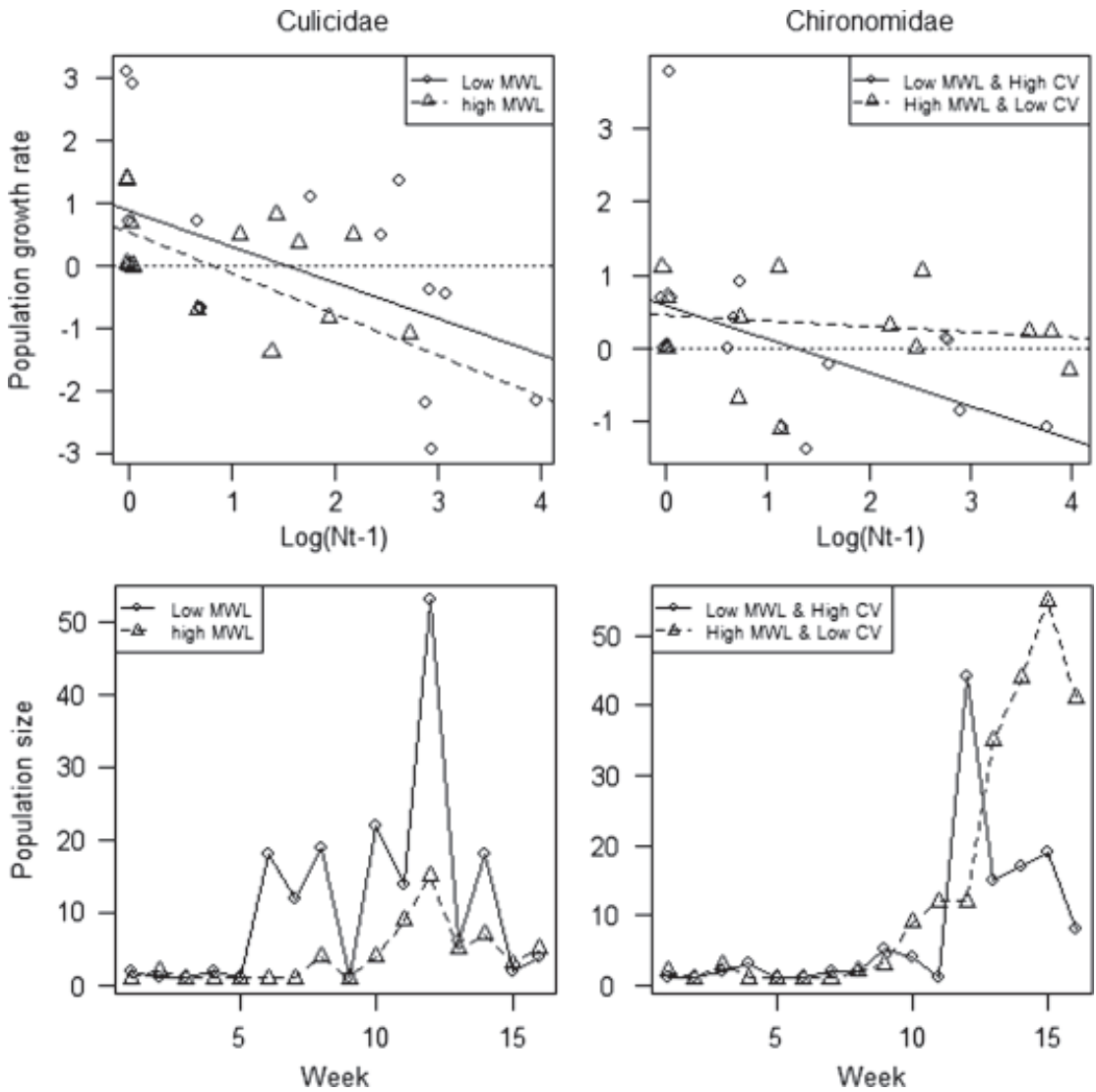

Figure 3. Representative time series for Culicidae in the left column and Chironomidae in the right column show the changes in growth rate and density dependence, with phase plots in the top row and raw data it the bottom row. Culicidae at low mean water levels (MWL) $(\mathrm{MWL}=6.6 \mathrm{~cm}, \mathrm{CV}=0.6$, solid line and circles) had the same density dependence (slope) but different growth rate (intercept) as Culicidae at high MWL (MWL $=23.1 \mathrm{~cm}, \mathrm{CV}=0.6)$ (top left); and the actual population data with similar density dependence but differing growth rates (bottom left. Chironomidae at low MWL $(6.6 \mathrm{~cm})$ and high CV $(0.5)$ (solid lines and circles) had a similar growth rate but drastically higher density dependence than a population at high MWL $(23.1 \mathrm{~cm})$ and low CV $(0.0)$ (top right) and the actual data with similar rates of increase but different-density dependent terms resulting in different population sizes (bottom right).

because oviposition represents an increase in 'births' of the larval population (which itself does not reproduce in a mesocosm). Female oviposition choice in Culicidae is sensitive to the presence of predators (Kiflawi et al. 2003, Blaustein et al. 2004), conspecifics (Edgerly et al. 1998), and habitat nutrient quality (Reiskind and Wilson 2004, Mokany and Mokany 2006). Because predator density did not vary among our treatments, nutrient concentration and conspecific abundance probably increased oviposition rates in low water tubs. The lower mean water means increased nutrient concentrations because the detritus type and amount was held constant. Once those treatments developed an initial population, females may have been attracted to mesocosms with high densities of conspecific larva as an indicator of future larval success (Edgerly et al. 1998). Culicidae abundance also varied with spatial position, temperature and dissolved $\mathrm{O}_{2}$ concentration in mesocosms, which may reflect direct and indirect effects of our treatments on larval abundance and female oviposition choices.

Much less is known about factors controlling population dynamics in Chironimidae (Schmid 1992), but space limitation for tube-building larvae (Hooper et al. 2003) may explain the pattern of stronger density-dependence under conditions of low mean water level and high fluctuations in water level (Fig. 2d). In contrast to the results for Culicidae, none of the measured covariates affected Chironomidae abundance. Instead, the abundance levels were driven only by the two experimental treatments, suggesting that, that post-colonization processes related directly to water level and variability were most important for Chironomidae.

Four caveats apply to our experimental study. First, the sampling regime and population growth equations we used do not allow us to infer the precise mechanisms of density-dependence, because we cannot distinguish between effects of migration from those of birth and death. Second, our mesocosms excluded amphibians and their larval stages, which act as important predators in many aquatic ecosystems (Wilbur 1987, Morin et al. 1988, Wilbur and Fauth 1990). We are currently running long-term experiments with larger experimental ponds that allow for amphibian migration. Finally, as in previous studies that used in situ sampling of invertebrates in the field (Gunnarson 1983, Caley 1995), it was necessary to lump species and genera into insect families. There are many examples of specieslevel differences among Culicidae (Spencer et al. 2002, Blaustein et al. 2004, Ellis 2008, Juliano 2009), so that density-dependence might be masked by pooling data at the family level. However it is difficult to see how pooling could 
cause spurious patterns of density-dependence that systematically map onto different hydroperiod regimes (Fig. 2). The fact that there were similar responses of the two families in different locations in the parameter space (Fig. 2, 4) also suggests that analyses are valid at the family level.

Finally we used a response surface design without replication. We had to choose between covering a larger parameter space or more replicates (Cottingham et al. 2005). We decided to cover a large parameter space because that would allow for the most robust inferences about future climates. One potential problem is that priority effects could result in alternative stable states (Chase 2003). However the patterns of abundance and population parameters measured across the treatment space suggest that the signal of hydroperiod is stronger than the noise from stochastically assembled communities (Chase 2010), although stochastic community formation cannot completely disregarded.

Our results support other correlative studies that suggest climate change, specifically changes in precipitation, can alter population dynamics (Coulson et al. 2001, Ogutu et al. 2008). We predict that with climate-induced decreases in mean water level and increases in variability, Culicidae will have increased population growth, and Chironimidae will show stronger density-dependence (Fig. 2), which could potentially increase the regional population size of Culicidae. Our results provide insights into the kind of population dynamics (Fig. 2), abundance patterns (Fig. 1) that can be expected with different climate change scenarios scenarios.

Acknowledgements - We gratefully acknowledge our two field assistants Christopher Graves and Cyrus Mallon and lab techs Autumn Amici and Erin Hayes-Pontius. David Brynn and Donald Tobi provided logistical support at Jericho Research Forest. Manuscript preparation was supported by a grant from Vermont EPSCoR. NJG acknowledges support of NSF grant DEB-0541936.

\section{References}

Ådahl, E. et al. 2006. From climate change to population change: the need to consider annual life cycles. - Global Change Biol. 12: 1627-1633.

Adler, P. B. and HilleRisLambers, J. 2008. The influence of climate and species composition on the population dynamics of ten prairie. - Ecology 89: 3049-3060.

Ainsworth, E. and Long, S. 2005. What have we learned from 15 years of free-air $\mathrm{CO} 2$ enrichment (FACE)? A meta-analytic review of the responses of photosynthesis, canopy. - New Phytol. 165: 351-371.

Armitage, P. D. et al. 1994. Chironomidae: the biology and ecology of non-biting midges. - Springer.

Benedetti-Cecchi, L. 2003. The importance of the variance around the mean effect size of ecological processes. - Ecology 84: 2335-2346.

Berryman, A. A. 1999. Principles of population dynamics and their application. - Garland Science.

Blaustein, L. et al. 2004. Oviposition habitat selection in response to risk of predation in temporary pools: mode of detection and consistency across experimental venue. - Oecologia 138: 300-305.

Boyce, M. S. et al. 2006. Demography in an increasingly variable world. - Trends Ecol. Evol. 21: 141-148.

Burnham, D. and Sorensen, E. 2003. Vermont Wetlands Bioassessment Program: an evaluation of the cemical, physical and biological characteristics of seasonal pools and Northern White Cedar Swamps. - Vermont Dept of Environmental Conservation and Vermont Dept of Fish and Wildlife, Nongame and Natural Heritage Program, Waterbury, VT.

Caley, M. J. 1995. Community dynamics of tropical reef fishes: local patterns between latitudes. - Mar. Ecol. Prog. Ser. 129: 7-18.

Chase, J. M. 2003. Experimental evidence for alternative stable equilibria in a benthic pond food web. - Ecol. Lett. 6: 733-741.

Chase, J. M. 2010. Stochastic community assembly causes higher biodiversity in more productive environments. - Science 328: 1388-1391.

Colburn, E. 2004. Vernal pools: natural history and conservation. McDonald and Woodward Publishing Company.

Cottingham, K. L. et al. 2005. Knowing when to draw the line: designing more informative ecological experiments. - Front. Ecol. Environ. 3: 145-152.

Coulson, T. et al. 2001. Age, sex, density, winter weather and population crashes in Soay sheep. - Science 292: 1528-1531.

Dennis, B. and Taper, M. L. 1994. Density-dependence in timeseries observations of natural populations: estimation and testing. - Ecol. Monogr. 64: 205-224.

Drake, J. M. 2005. Population effects of increased climate variation. - Proc. R. Soc. B 272: 1823-1827.

Edgerly, J. S. et al. 1998. A seasonal shift in egg-laying behaviour in response to cues of future competition in a treehole mosquito. J. Anim. Ecol. 67: 805-818.

Ellis, A. M. 2008. Incorporating density dependence into the oviposition preference - offspring performance hypothesis. - J. Anim. Ecol. 77: 247-256.

Frumhoff, P. et al. 2006. Climate change in the US Northeast. Union of Concerned Scientists.

Gelman, A. and Rubin, D. B. 1992. Inference from iterative simulation using multiple sequences. - Stat. Sci. 7: 457-472.

Graham, A. 2008. Mosquitoes of Vermont. - Vermont Agency of Agric., Div. of Agric. Manage. and Environ. Stewardship, Montepelier, Vermont, USA.

Gunnarsson, B. 1983. Winter mortality of spruce living spiders: effect of spider interactions and bird predation. - Oikos 40: 226-233.

Halkka, A. et al. 2006. Lagged effects of North Atlantic Oscillation on spittlebug Philaenus spumarius (Homoptera) abundance and survival. - Global Change Biol. 12: 2250-2262.

Hayhoe, K. et al. 2008. Regional climate change projections for the northeast USA. - Mitigation Adaptation Strategies Global Change 13: 425-436.

Hooper, H. L. et al. 2003. The influence of larval density, food availability and habitat longevity on the life history and population growth rate of the midge Chironomus riparius. - Oikos 102: 515-524.

Husak, G. J. et al. 2007. Use of the gamma distribution to represent monthly rainfall in Africa for drought monitoring applications. - Int. J. Climatol. 27: 935-944.

Inouye, B. D. 2001. Response surface experimental designs for investigating interspecific competition. - Ecology 82: 2696-2706.

Ives, A. R. 1995. Predicting the response of populations to environmental change. - Ecology 76: 926-941.

Ives, A. R. et al. 2003. Estimating community stability and ecological interactions from time-series data. - Ecol. Monogr. 73: 301-330.

Juliano, S. A. 2009. Species interactions among larval mosquitoes: context dependence across habitat gradients. - Annu. Rev. Entomol. 54: 37-56.

Kendon, E. J. et al. 2008. Robustness of future changes in local precipitation extremes. - J. Climate 21: 4280-4297.

Kiflawi, M. et al. 2003. Oviposition habitat selection by the mosquito Culiseta longiareolata in response to risk of predation 
and conspecific larval density. - Ecol. Entomol. 28: 168173.

Krebs, C. J. and Berteaux, D. 2006. Problems and pitfalls in relating climate variability to population dynamics. - Climate Res. 32: 143-149.

Lima, M. et al. 2008. Chihuahuan Desert kangaroo rats: nonlinear effects of population dynamics, competition and rainfall. Ecology 89: 2594-2603.

McArdle, B. H. et al. 1990. Variation in the size of animal populations - patterns, problems and artifacts. - J. Anim. Ecol. 59: 439-454.

McCoy, M. W. and Bolker, B. M. 2008. Trait-mediated interactions: influence of prey size, density and experience. - J. Anim. Ecol. 77: 478-486.

Mokany, A. and Mokany, K. 2006. Effects of habitat permanence cues on larval abundance of two mosquito species. - Hydrobiologia 563: 269-276.

Moore, M. V. et al. 1997. Potential effects of climate change on freshwater ecosystems of the New England/Mid-Atlantic Region. - Hydrol. Processes 11: 925-947.

Morin, P. J. et al. 1988. Competition between aquatic insects and vertebrates - interaction strength and higher-order interactions. - Ecology 69: 1401-1409.

Mysterud, A. et al. 2001. Nonlinear effects of large-scale climatic variability on wild and domestic herbivores. - Nature 410: 1096-1099.

Ogutu, J. O. et al. 2008. Rainfall influences on ungulate population abundance in the Mara-Serengeti ecosystem. - J. Anim. Ecol. 77: 814-829.

Plummer, M. et al. 2006. CODA: convergence diagnosis and output analysis for MCMC. - R News 6: 7-11.

Reiskind, M. H. and Wilson, M. L. 2004. Culex restuans (Diptera: Culicidae) oviposition behavior determined by larval habitat quality and quantity in southeastern Michigan. - J. Med. Entomol. 41: 179-186.

Richmond, C. E. et al. 2007. Climate change and increased environmental variability: demographic responses in an estuarine harpacticoid copepod. - Ecol. Model. 209: 189-202.
Royama, T. 1992. Analytical population dynamics. - Chapman and Hall.

Schmid, P. E. 1992. Population-dynamics and resource utilization by larval Chironomidae (Diptera) in a backwater area of the River Danube. - Freshwater Biol. 28: 111-127.

Sæther, B. et al. 2000. Population dynamical consequences of climate change for a small temperate songbird. - Science 287: $854-856$.

Spencer, M. et al. 2002. Oviposition habitat selection by mosquitoes (Culiseta longiareolata) and consequences for population size. Ecology 83: 669-679.

Sun, Y. et al. 2007. How often will it rain? - J. Climate 20: 4801-4818.

Suttle, K. B. et al. 2007. Species interactions reverse grassland responses to changing climate. - Science 315: 640-642.

Tavecchia, G. et al. 2007. Density-dependent parameters and demographic equilibrium in open populations. - Oikos 116: 1481-1492.

Turner, J. T. et al. 2006. Zooplankton of Massachusetts Bay, USA, 1992-2003: relationships between the copepod Calanus finmarchicus and the North Atlantic Oscillation. - Mar. Ecol. Prog. Ser. 311: 115-124.

van de Pol, M. et al. 2010. Effects of climate change and variability on population dynamics in a long-lived shorebird. - Ecology 91: 1192-1204.

Visser, M. E. and Holleman, L. J. M. 2001. Warmer springs disrupt the synchrony of oak and winter moth phenology. - Proc. R. Soc. B 268: 289-294.

Wilbur, H. M. 1987. Regulation of structure in compelx-systems experimental temporary pond communities. - Ecology 68: 1437-1452.

Wilbur, H. M. and Fauth, J. E. 1990. Experimental aquatic food webs - interactions between 2 predators and 2 prey. - Am. Nat. 135: 176-204.

Yang, G. J. et al. 2008.Importance of endogenous feedback controlling the long-term abundance of tropical mosquito species. Popul. Ecol. 50: 293-305.

Zedler, P. H. 2003. Vernal pools and the concept of "isolated wetlands". - Wetlands 23: 597-607. 